\title{
Particle concentration and flux dynamics in the atmospheric boundary layer as the indicator of formation mechanism
}

\author{
J. Lauros ${ }^{1}$, A. Sogachev ${ }^{2}$, S. Smolander ${ }^{1}$, H. Vuollekoski ${ }^{1}$, S.-L. Sihto ${ }^{1}$, I. Mammarella ${ }^{1}$, L. Laakso ${ }^{1,3,4}$, Ü. Rannik ${ }^{1}$, \\ and M. Boy ${ }^{1}$ \\ ${ }^{1}$ Department of Physics, University of Helsinki, Finland \\ ${ }^{2}$ Wind Energy Division, Ris $\varnothing$ National Laboratory for Sustainable Energy, Technical University of Denmark, Roskilde, \\ Denmark \\ ${ }^{3}$ Finnish Meteorological Institute, Helsinki, Finland \\ ${ }^{4}$ School of Physical and Chemical Sciences, North-West University, Potchefstroom, Republic of South Africa
}

Received: 11 July 2010 - Published in Atmos. Chem. Phys. Discuss.: 24 August 2010

Revised: 30 May 2011 - Accepted: 7 June 2011 - Published: 16 June 2011

\begin{abstract}
We carried out column model simulations to study particle fluxes and deposition and to evaluate different particle formation mechanisms at a boreal forest site in Finland. We show that kinetic nucleation of sulphuric acid cannot be responsible for new particle formation alone as the simulated vertical profile of particle number concentration does not correspond to observations. Instead organic induced nucleation leads to good agreement confirming the relevance of the aerosol formation mechanism including organic compounds emitted by the biosphere.

The simulation of aerosol concentration within the atmospheric boundary layer during nucleation event days shows a highly dynamical picture, where particle formation is coupled with chemistry and turbulent transport. We have demonstrated the suitability of our turbulent mixing scheme in reproducing the most important characteristics of particle dynamics within the boundary layer. Deposition and particle flux simulations show that deposition affects noticeably only the smallest particles in the lowest part of the atmospheric boundary layer.
\end{abstract}

\section{Introduction}

The formation of new particles remains one of the greatest challenges in atmospheric aerosols research. In spite of decades of intensive research, no one-for-all solution has

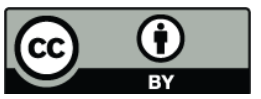

Correspondence to: J. Lauros (johanna.lauros@alumni.helsinki.fi) been presented. As meteorological conditions and the composition of vapours vary spatially in the atmosphere, several formation mechanisms have been proposed.

Among the most cited mechanisms are the binary (Vehkamäki et al., 2002) and ternary (Napari et al., 2002) nucleation. However, they predict the existence of 4-10 sulphuric acid molecules in a critical cluster, whereas many experimental studies have found a linear to quadratic relationship between the new particle formation rate and the sulphuric acid concentration (Weber et al., 1996; Kulmala et al., 2006; Sihto et al., 2006; Riipinen et al., 2007; Kuang et al., 2008; Sihto et al., 2009; Vuollekoski et al., 2010). In accordance with these recent findings, semi-empirical nucleation mechanisms have been presented, such as the activation of pre-existing clusters (Hoppel et al., 1994; Kulmala et al., 2006).

Lately, the role of organics in new particle formation has gained more and more interest. Some studies have found that the growth rate calculated from the concentration of sulphuric acid is not enough to explain the growth of ultrafine particles (Weber et al., 1997; Birmili et al., 2003; Boy et al., 2005). This suggests the condensation of an additional, lowvolatile vapour. Recently, the participation of such vapour in the nucleation step itself has been studied (e.g. Bonn et al., 2009; Paasonen et al., 2010; Vuollekoski et al., 2010).

In the meteorological sense, the mixing of atmospheric constituents - in particular aerosol particles - is challenging. The simplest, first order mixing parametrisations (see e.g. Stull, 1989), the so called gradient transport theory or Ktheory, have not succeeded to present turbulent mixing in all atmospheric layers and conditions, so higher order models

Published by Copernicus Publications on behalf of the European Geosciences Union. 
have been developed and utilised also in aerosol studies (e.g. Hellmuth, 2006a,b,c,d). Some parametrisations add a separate nonlocal gradient transport term to the flux equation (e.g. Noh et al., 2003). The idea is that the transport should depend strongly on the surface gradient, instead of the local gradient of the studied quantity. This approach may be convenient when modelling heat flux and other similarly behaving quantities. In the case of aerosol flux, the surface gradient of particle concentration does not describe the strength of the mixing in the same manner as it does for e.g. temperature gradient. The results may be opposite to those intended, when particle concentration increases upwards and the added term leads to weaker mixing than the parametrisation without the nonlocal gradient term.

It would be easy to assume that if a model includes more complex structures of turbulence, then this improves the results significantly. However, complex parametrisations may be sensitive to particular parameter values, which may be unreliable. For this study, we have chosen a one-and-half order parametrisation (Boy et al., 2011) which presents mixing more reliably than the earlier utilised first order schemes (Boy et al., 2006) and is easier to utilise in aerosol flux calculations than the nonlocal schemes mentioned above.

In this article, we aim to enhance knowledge in particle formation mechanisms utilising fluxes and vertical distribution of particles in the atmospheric boundary layer (ABL). As we are interested in particle formation especially in the lowest part of the atmosphere, we concentrate on testing theories of organic-sulphuric acid nucleation mechanisms and compare the results with the conventional kinetic nucleation theory. As ion-induced nucleation is typically of minor importance in Hyytiälä, on average $\sim 10 \%$ of the total nucleation (Laakso et al., 2004; Gagné et al., 2008; Boy et al., 2008; Manninen et al., 2009), in this study we investigate neutral pathways. In addition, we study the effect of turbulent mixing, dilution and deposition on particle formation, and evaluate the adequacy of the developed model in aerosol studies.

\section{Measurements}

The measurements were carried out at the SMEAR II station in Southern Finland. A detailed description of the station and instrumentation is given by Kulmala et al. (2001) and at http://www.atm.helsinki.fi/SMEAR/. The particle size distributions between 3-1000 $\mathrm{nm}$ were measured by a twin differential mobility particle sizer (TDMPS) within a vegetative canopy. In addition, vertical profiles of meteorological variables (temperature, humidity) and number concentration of particles ( $>10 \mathrm{~nm}$ in diameter, measured by two condensation particle counters) were measured on hot-air balloon flights (Laakso et al., 2007).

\section{Model}

The utilised one-dimensional model of the ABL is a further development of the model MALTE (Model to predict new Aerosol formation in the Lower TropospherE) which is described in detail by Boy et al. (2006, 2008). The model reproduces the diurnal variation of boundary layer meteorology, chemistry, emissions and particle formation. We have improved the meteorology scheme (turbulence, radiation), as compared to MALTE, by utilising a one-dimensional version of the model SCADIS (Sogachev et al., 2002; Sogachev and Panferov, 2006; Sogachev, 2009). In our simulations, the model consists of 52 layers, of which 18 are within the vegetative canopy in the lowest $15 \mathrm{~m}$. The model vegetation consists of pine.

\subsection{Meteorological scheme}

We replaced the original turbulence scheme in MALTE with that of SCADIS to get more reliable results, considering vertical turbulent (heat, vapour and aerosol) fluxes. The fluxes are expressed as a product of the turbulent diffusion coefficient and the gradient of a mean quantity. The atmospheric boundary layer model SCADIS originally includes a set of movement equations, the continuity equation, equations for moisture and heat transport, and it is also able to implement transport equations for passive tracers of interest. The timemarching method is used to solve the nonlinear two-point boundary-value problems. SCADIS applies a one-and-halforder closure scheme, when the equation for turbulent kinetic energy and the equation of a supplementary characteristic (in SCADIS that is the specific dissipation) have to be solved to estimate the diffusion coefficient. Considering the vegetation as a multi-layer medium and implementing parametrisations for radiation transfer, drag forces on leaves and stomatal conductance, SCADIS properly describes the exchange between the vegetative canopy and the atmosphere. In our simulations, observations of direct and diffuse solar radiation above the canopy were utilised as border values for the radiation transfer scheme.

\subsection{Chemistry and emissions}

The model presents time-dependent concentrations of 45 chemical species which result from 112 reactions. Sulphuric acid and reaction products of organic vapours (monoterpenes) are the most essential simulated vapours in our study, as these participate in nucleation.

KPP - the Kinetic PreProcessor (Damian, 2002; Sandu and Sander, 2006) is now used in MALTE to translate the reaction equations (for details see Boy et al., 2006) into Fortran 90 code, that performs the time integration of the kinetic system. Of the several numerical solvers for systems of differential equations available in KPP, we used the LSODE solver (Radhakrishnan and Hindmarsh, 1993; Sandu 
et al., 1997). The KPP-produced Fortran code is then called from the main MALTE code. Some minimal changes to the KPP-produced code were performed. The chemistry and meteorology are combined in a typical split-operator approach. The meteorology, including atmospheric mixing of the chemical species, is simulated with a $10 \mathrm{~s}$ time step and after each 6 steps emissions and chemical reactions, separately for each atmosphere layer, are simulated for $60 \mathrm{~s}$. Thus the changes in the chemical concentrations after the chemistry step would appear instantaneously from the meteorology model point of view.

The emissions of monoterpenes from the canopy are calculated with MEGAN (Model of Emissions of Gases and Aerosols from Nature), which is described by Guenther et al. (2006). The emission rates depend on leaf temperature and the available solar radiation on sun and shade, calculated separately for every model level.

\subsection{Particle formation and growth}

The aerosol dynamic processes are simulated with the multicomponent aerosol dynamics model UHMA (Korhonen et al., 2004). The scheme includes representations of nucleation mechanisms, activation of nano-size clusters following the nano-Köhler theory (Kulmala et al., 2004), condensation and coagulation (see also Boy et al., 2006). We consider different formation paths for new secondary particles but primary particle emissions are ignored. The first mechanism is called kinetic type nucleation and was first proposed by McMurry and Friedlander (1979). In kinetic nucleation, critical clusters are formed by collisions of sulphuric acid molecules or other molecules containing sulphuric acid, e.g. ammonium bisulphate molecules. The upper limit for kinetic nucleation, the kinetic limit, is set by the collision rate of molecules given by the kinetic theory of gases. Here we let the collision frequency function be a free parameter and calculate nucleation rate as:

$J=K \times\left[\mathrm{H}_{2} \mathrm{SO}_{4}\right]^{2}$

The coefficient $K$ in our study was set to $5 \times 10^{-13} \mathrm{~cm}^{3} \mathrm{~s}^{-1}$, based on the best fit after a comparison of the simulated and observed particle concentrations on the studied time period. This kinetic coefficient $K$ contains the details of the nucleation process, especially the probability that a collision of two sulphuric acid containing molecules results in the formation of a stable critical cluster. As the determined value of the semi-empirical coefficient $K$ varies over orders of magnitude (Sihto et al., 2006; Riipinen et al., 2007), the coefficient may depend on factors which lead to a vertical dependence. However, the potential vertical dependence has not been studied and therefore we have settled to a constant value of the coefficient $K$.

The second nucleation mechanism, organic-sulphuric acid nucleation, is presented assuming that new particles are formed through collisions between sulphuric acid molecules and molecules which are reaction products of organic vapours (MoRP, monoterpenes reaction products). So the formation rate depends on the concentration of vapours $\left(\mathrm{H}_{2} \mathrm{SO}_{4}, \mathrm{MoRP}\right)$ and molecular collision probability:

$J=P v\left[\mathrm{H}_{2} \mathrm{SO}_{4}\right][\mathrm{MoRP}]$.

Here $v$ is the collision rate and the constant $P$ describes the probability that a collision leads to new particle formation. Similarly as above we defined the value of $P$ based on the best fit for studied formation paths. The value of $P$ was set to $1-2 \times 10^{-4} \mathrm{~cm}^{-3}$, depending on the (concentration of) organic reaction products which are participating nucleation: $1 \times 10^{-4} \mathrm{~cm}^{-3}$ for $\mathrm{OH}$ oxidation products and $2 \times 10^{-4} \mathrm{~cm}^{-3}$ for $\mathrm{O}_{3}$ oxidation products. As the formation rate depends on organic vapour concentration, the expected maximum of particle formation rate is located at the surface close to organic vapour sources and the rate decreases upwards.

Nucleation is followed by growth, according to the nanoKöhler theory, having sulphuric acid and reaction products of organics, oxidised by $\mathrm{OH}$, as a condensing vapour. Simultaneously water, sulphuric acid and reaction products of organics, oxidised by $\mathrm{OH}, \mathrm{NO}_{3}$ and $\mathrm{O}_{3}$, participate in the conventional condensational growth of particles. In the presented simulations we have assumed that $5 \%$ of organic oxidation products are able to condense on particles. The value has led to good agreement with observed growth rates at the surface in an earlier (Boy et al., 2006) and this study. Similarly as the prefactors in Eqs. (1) and (2), the proportion of condensable vapours may depend on circumstances (altitude). However, we are not able to estimate the vertical dependence of proportion of condensable vapours on altitude, as we have measurements only on particles larger than $10 \mathrm{~nm}$ in diameter.

\subsection{Particle deposition to the canopy}

In the earlier model version deposition to the canopy was presented by a bulk parametrisation, as the model had only one level describing the removal effect. As the new model version has several levels within the canopy, a more sophisticated deposition parametrisation is possible.

We follow Petroff et al. (2008) to parametrise deposition to needles. The vegetation collection rate $r_{k}\left(\mathrm{~s}^{-1}\right)$ due to process $k$ in a layer,

$r_{k}=a f_{k} v_{k}$

depends on the surface area of needles $a$ and the elemental collection velocity $v_{k}$. The factor $f_{k}$ describes the ratio of the averaged and the elemental collection velocity and depends on an angular and size distribution of needles in a layer. The vegetation removal rate $R_{k}\left(\mathrm{~cm}^{-3} \mathrm{~s}^{-1}\right)$ is a product of the vegetation collection rate and the particle concentration $C$ :

$R_{k}=r_{k} \times C$

We assume that the total deposition is a sum of individual processes and parametrise separately any deposition due to 
Brownian diffusion, gravitational settling, interception and inertial impaction. The two latter processes are more dependent on wind velocity than Brownian diffusion. The influence of interception exceeds the effect of Brownian diffusion already at low wind velocities, when particles are larger than $100 \mathrm{~nm}$ (see Petroff et al., 2008). When particle diameter is $25 \mathrm{~nm}$, interception begins to dominate if wind speed exceeds $4 \mathrm{~m} \mathrm{~s}^{-1}$. For interception and impaction calculation, we assume that the angle distribution of needles in the space, and the size distribution of diameter, are both uniform.

Brownian diffusion due to thermal motion is most important for small particles. The elemental collection velocity due to Brownian diffusion is defined for needles as (Petroff et al., 2008)

$$
v_{B}=\frac{\operatorname{Sh} D_{B}}{d_{n}}
$$

where $D_{B}\left(\mathrm{~m}^{2} \mathrm{~s}^{-1}\right)$ is the diffusivity of a particle and the mean diameter of needles $d_{n}$ was set to $1 \mathrm{~mm}$. The Sherwood number is defined as $S h=C_{B} S c^{1 / 3} R e^{n_{B}}$ where $R e$ is the Reynolds number and $C_{B}$ and $n_{B}$ are adjusted parameters which depend on the flow regime through $R e$.

Deposition velocity is defined as

$V_{d}(z)=-\frac{F_{t}(z)}{C(z)}+W_{s}$

where $F_{t}$ is the turbulent flux and $W_{s}$ the settling velocity. At the surface we calculate the deposition velocity as Petroff et al. (2008):

$V_{d g}=3 \sqrt{3}(29 \pi) S c^{-2 / 3} u_{*}+W_{s}$

where $S c$ is the Schmidt number and $u_{*}$ the friction velocity (in this study at the first model level above the surface). The settling velocity is calculated as described by Rannik et al. (2003). For details of parametrisations, see Petroff et al. (2008).

\section{Results}

We simulated new particle formation on 12-14 March 2006. On these event days hot-air balloon flights were carried out (Laakso et al., 2007). The initial vapour concentrations of most species, especially the organic reaction products, were set to zero at the start of the model run. The concentration of reaction products of organics achieved steady state within a few hours after the onset of emissions. As the higher generation reaction products of organics are less volatile than first generation products, the reaction rates of organics were halved. For several other gases like $\mathrm{CO}, \mathrm{SO}_{2}, \mathrm{NO}, \mathrm{NO}_{\mathrm{x}}$ and ozone, measurements from the SMEAR II station were used as inputs through the model simulation duration. The vertical profiles of input gases were set to be uniform. Sulphuric acid was calculated from oxidation of observed $\mathrm{SO}_{2}$ and organic vapours originated from calculated canopy emissions.
$\mathrm{H}_{2} \mathrm{SO}_{4}$ was not measured at the SMEAR II station on March 2006 but the simulated concentrations $\left(10^{4}-10^{7} \mathrm{~cm}^{-3}\right)$ are consistent with observations on Spring 2007 (Petäjä et al., 2009). The initial particle distribution corresponded to surface observations in the ABL (below $300 \mathrm{~m}$ ) and was set to 0.2 of the observed concentration at higher altitudes in the free troposphere. Similarly the initial $\mathrm{SO}_{2}$ concentration was set to 0.2 of the observed concentration above the ABL and later it was defined to be 0.2 of observed surface concentration at minimum. The sensitivity studies show that even if $\mathrm{SO}_{2}$ concentration in the free troposphere is set to the same as the observed at the surface, our conclusions would not change.

\subsection{Evaluation with meteorology}

Meteorological conditions were dominated by a high pressure system, the centre of which moved from the Scandinavian Peninsula to Finland. Thereby the air flow turned from north to east during the studied period. The simulated mixing height, defined in the simulations as an altitude where the Richardson number exceeds 0.25 , is typical for spring time in Finland and the early growth was consistent with the SODAR measurements at the SMEAR II station (Fig. 1a). However, the simulated humidity profiles show underestimation in concentration in the free troposphere during the afternoon. As the source of humidity is at the surface, this together with the temperature profiles indicate underestimation in the mixing strength, especially above the ABL (Fig. 1b). Similarly a comparison with radiosoundings in Jokioinen refers to underestimation of mixing, because the simulated $\mathrm{ABL}$ height does not achieve similar heights as defined from the soundings. The weak mixing affects vapour concentrations leading to a strong concentration gradient between the ABL and the free troposphere. This is discussed in more detail in Sects. 4.2.2 and 4.3.

\subsection{Particle formation paths}

\subsubsection{Kinetic nucleation}

Kinetic nucleation (Eq. 1) reproduces the observed particle formation events at the surface even if the observed formation events are not as clear as the simulated ones (Fig. 2a and b). Even if kinetic nucleation is able to reproduce surface observations, the simulated vertical particle profile does not correspond to the observed one (Fig. 3). The kinetic nucleation prefers new particle formation in the free troposphere where pre-existing particle concentration is low. The nucleation rate follows diurnal variation of sulphuric acid but the number concentration of aerosols increases constantly above the ABL, due to a low sink and higher sulphuric acid concentration above. The observed profiles for particles greater than $10 \mathrm{~nm}$ in diameter refers to particle formation within the $\mathrm{ABL}$, as the number concentration decreases notably just 

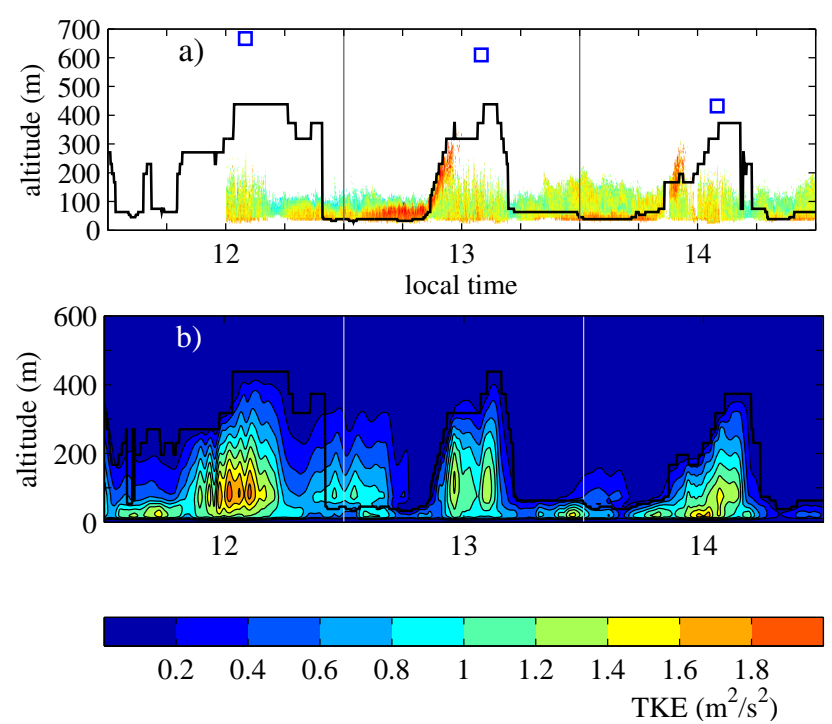

Fig. 1. (a) Mixing height (i) as observed by SODAR, shown by colours, red colour shows the strongest echo and thereby the altitude of temperature inversion, see Lauros et al. (2007), and (ii) as determined from radiosonde measurements in Jokioinen, $100 \mathrm{~km}$ to the South from SMEAR II, shown by blue squares, and (iii) as simulated with MALTE, shown by black curve. (b) Turbulence kinetic energy (TKE) from simulations, black curve same as in (a).

above the ABL. Based on our simulations and earlier studies (Makkonen et al., 2009), kinetic nucleation cannot be the prime particle formation mechanism in the lower troposphere at the boreal forest site. The conclusion does not change even if we assume a uniform $\mathrm{SO}_{2}$ distribution only within the $\mathrm{ABL}$, and the concentration above the $\mathrm{ABL}$ is set to 0.5 of the observed value (Fig. 3a).

\subsubsection{Organic-induced formation}

We have simulated different paths for new particle formation, and tested organic components which participate in nucleation and nano-Köhler growth. When nucleation rate depends on organics (monoterpenes) oxidised by $\mathrm{O}_{3}$, particles are formed even in the night because the concentration of oxidation products does not decrease significantly. This leads to the presence of smallest particles in the night, whereas 3-6 $\mathrm{nm}$ particles are not observed similarly during this time period (Fig. 2c). Decreasing $P$ in Eq. (2) does not help as the formation rate decreases similarly at observed event time and the diurnal variation in concentration of organics oxidised by $\mathrm{O}_{3}$ is too small. The result is improved if the nucleation rate depends on reactions products of monoterpenes and $\mathrm{OH}$ instead of $\mathrm{O}_{3}$ as clear events are produced (Fig. 2d). Recent laboratory experiments (Hao et al., 2009) indicate that reaction products from $\mathrm{OH}$ oxidation of organics are more probable to nucleate than reactions products from $\mathrm{O}_{3}$ oxidation.
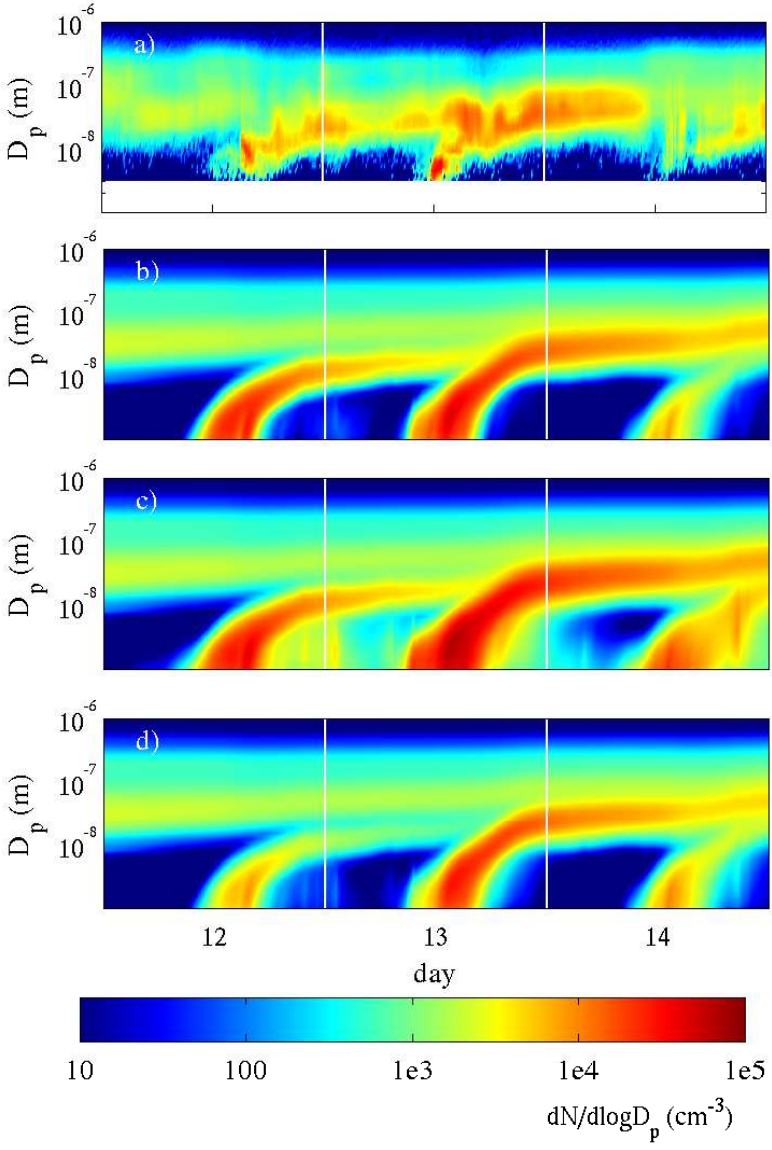

Fig. 2. (a) Observed particle formation events. (b) Typical event simulation for kinetic nucleation (Eq. 1). (c) Typical event when the nucleation rate depends on reaction products of monoterpenes with $\mathrm{O}_{3}$ (Eq. 2) and (d) typical event when the nucleation rate depends on reaction products of monoterpenes with $\mathrm{OH}$ (Eq. 2). In presented simulations the condensing organic vapour participating nano-Köhler growth is composed from reaction products of monoterpenes with $\mathrm{OH}$.

Simulated new particle formation rate decreases upwards, as the organic gas concentration decreases. This leads to a similar vertical distribution of particles $(>10 \mathrm{~nm}$ in diameter) as observed (Fig. 3a): the concentration is constant within the ABL due to strong mixing but decreases substantially above the ABL. Between 500-1200 m, the simulated concentrations follow the initial particle profile, set in the begin of the simulation, instead of the observations. As the simulated concentration of the smallest particle is similarly very low at these altitudes, the underestimation of larger particles does not result from slow growth of particles. A reason can be too weak mixing and flow of $10-1000 \mathrm{~nm}$ particles from the ABL or lack of advection of particles in the free troposphere (different background aerosol distribution) that is not included in 1D modelling. As the concentration of nucleating and condensing organic vapours is probably underestimated 

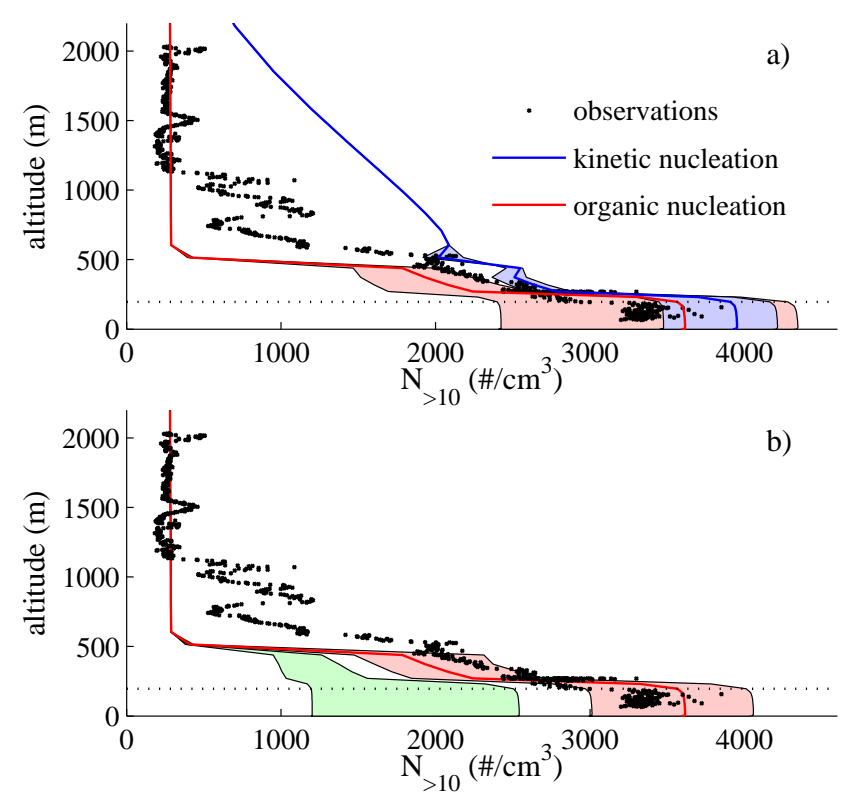

Fig. 3. Observed and simulated particle number concentration $N_{>10 \mathrm{~nm}}$ on 13 March 2006 when the particles are formed by organic and kinetic nucleation. The ABL height is shown by black dotted horizontal line. (a) The shaded areas show the range of concentration when reaction rate of organics is multiplied by $0.2-$ 1. (b) The shaded areas show the range of particle concentration when $2-10 \%$ of organic vapours can condense on particles (red) and when (i) organics are nonvolatile, (ii) organics are nonvolatile and $P=10^{-3} \mathrm{~cm}^{-3}$ or (iii) organics cannot condense on particles below $3 \mathrm{~nm}$ (green).

due to weak mixing just above the ABL, the underestimation of local particle formation is a plausible reason. Earlier observations confirm that new particle formation is possible in the residual layer (Stratmann et al., 2003; Laakso et al., 2007).

The concentration gradient between the ABL and the residual layer decreases if the nucleating and condensing reaction products of organics are higher generation products, in other words, if the nucleating organic products are formed slower than the first order products (Fig. 3a). However, this does not affect the particle concentration above the residual layer in the free troposphere. We have tested the model variables, e.g., different condensing fraction of organics, different prefactors for nucleation, possibility that organics do not condense on particles below $3 \mathrm{~nm}$ or organics are nonvolatile. As we can expect, the number concentration of particles $(>10 \mathrm{~nm})$ increases, if a reduced amount of organics is able to condense on particles. Also the gradient between the $\mathrm{ABL}$ and the residual layer seems to be stronger in this case. All tested cases produce a surface event or a vertical profile (Fig. 3b) which is less consistent with the observations than our basic case. In the case of kinetic nucleation, the particle concentration in the free troposphere is overestimated without an exception.

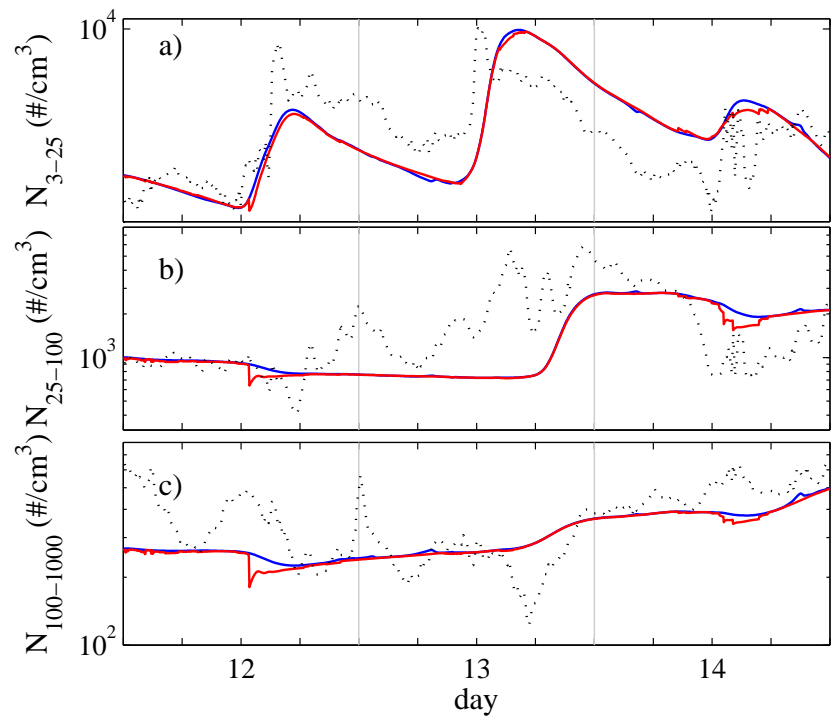

Fig. 4. Simulated particle concentration (a) $N_{3-25} \mathrm{~nm}$, (b) $N_{25-100 \mathrm{~nm}}$ and (c) $N_{100-1000 \mathrm{~nm}}$ at the top of the ABL (red curve) and at the surface (blue curve). The observed aerosol concentration at the surface is shown by black dotted curve.

Organic-induced nucleation allows us to study mixing of particles, when most of the new particles are formed in the lower half of the ABL. In following simulations, nucleation rate depends on reaction products of organics oxidised by $\mathrm{OH}$.

\subsection{Dilution due to entrainment and deposition}

\subsubsection{Entrainment and particle fluxes}

Decrease in surface particle concentration has been recognised regularly in mornings before a particle formation event occurs (Boy et al., 2004). The decrease has been explained by an onset of mixing and flow of cleaner air from the free troposphere to the surface. Dilution cannot be positively identified in our measurements because the observed particle concentrations of 25-100 and 100-1000 nm particles vary in a short time scale. The concentrations decrease simultaneously before the onset of particle formation only on 13 March (Fig. 4). The simulations show more clearly dilution at the top of the ABL followed by a weaker dilution effect at the surface. The simulated dilutions occur at noon after the onset of new particle formation and therefore the decreasing sink, due to dilution of background aerosol concentration, cannot activate particle formation in our simulation. The simulated number concentration of the largest particles follows well the trend of measurements but the short scale variation cannot be captured (Fig. 4c). The simulated concentration of the smallest particles starts to increase simultaneously with the measured concentration but the growth is slightly weaker than the measurements indicate (Fig. 4a, b). The early increase of 
the observed Aitken mode concentration on 13 March results from the new particle formation event on previous day (see Fig. 2a).

When the boundary layer grows and the mixing reaches upper cleaner air, this leads to a concentration gradient and particle flux upwards toward lower concentrations (Fig. 5). Flux of larger particles $(>25 \mathrm{~nm})$ (Fig. $5 \mathrm{c}, \mathrm{d})$ is constantly upwards achieving the maximum strength at the upper part of the ABL after noon.

The conditions for organic-induced particle formation and growth are most favourable at the surface which creates a vertical concentration gradient and upward flux of the smallest particles. The direction of particle flux of the smallest particles turns downwards after the ABL growth ends (Fig. 5a). The downward flux of particles requires a downward decreasing concentration which can result from the removal of small particles near surface. The flux turns even if deposition to the canopy is ignored. Therefore the explanation is coagulation of small particles near the surface. The concentration of accumulation mode particles is higher and the coagulation sink of the smallest particles is stronger in the lowest part of the ABL than at higher altitudes. The deposition, however, explains the constant downward flux of the smallest particles within the vegetative canopy. Similarly as for 3-6 nm particles, the flux of 3-25 nm particles is downwards and opposite to the larger particle flux during night. The flux does not turn upwards until in forenoon when the fresh-formed particles have grown into the size class. The flux in both the smallest size classes, 3-6 $\mathrm{nm}$ and 3-25 nm, turns upwards simultaneously as the lower limit of size classes is the same. In the afternoon, the flux of 3-6 nm particles turns downwards before $3-25 \mathrm{~nm}$ particle flux. This can be understood as the number concentration of 6-25 nm particles increases near the surface still after 3-6 $\mathrm{nm}$ particles have reached the maximum concentration. In other words, due to favourable particle growth at the surface, the vertical distribution of 3-25 nm particles evens out slower and the flux continues upwards longer than for the smallest studied size range.

The change of particle concentration depends on the gradient of turbulent fluxes and other terms related to aerosol dynamics:

$\frac{d C}{d t}=-\frac{d F_{t}}{d z}+S_{a d}$

Here $S_{a d}$ represents particle formation, sources and removal processes (deposition, coagulation, sinks). Under steadystate conditions the particle concentration does not change in the layer if the flux is spatially constant - as many particles are flowing in and out of the layer. We have calculated the effect of fluxes on particle concentration from the simulated particle fluxes (Fig. 6). Even if the particle flux is strong within the ABL, it leads only to minor change in particle concentration of the largest particles as the gradient of particle flux is insignificant. The concentration of the largest particles changes moderately and mainly just above the ABL
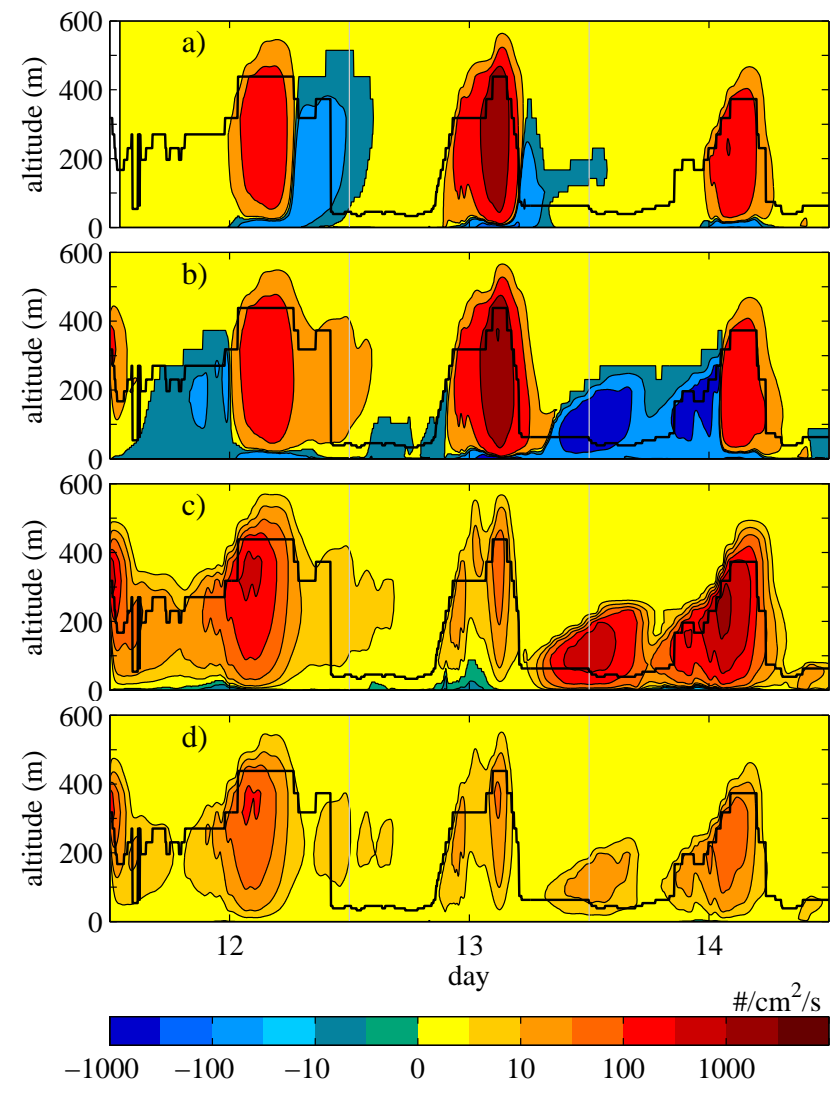

Fig. 5. Turbulent particle flux $\left(\mathrm{cm}^{-2} \mathrm{~s}^{-1}\right)$ for (a) $3-6 \mathrm{~nm}$ (b) $3-$ $25 \mathrm{~nm}$, (c) $25-100 \mathrm{~nm}$ and (d) $100-1000 \mathrm{~nm}$ particles. Black solid curve represents simulated mixing height.

where the strength of mixing changes strongly and the particle concentration gradient is large. Mixing mostly affects the smallest 3-6 nm particles in the ABL. The flux results from strong new particle formation in the ABL which creates a particle concentration gradient between the $\mathrm{ABL}$ and the free troposphere. The nighttime downward flux of 3$25 \mathrm{~nm}$ particles aims to decrease the particle concentration above the ABL and increase the concentration near the surface (Fig. 6b). However, the removal processes exceed the effect of downward flux and the particle concentration decreases at the surface in the night (Fig. 4a).

\subsubsection{Deposition to canopy}

In addition to coagulation, turbulent mixing and entrainment to the free troposphere, deposition in the vegetative canopy removes particles in the ABL. Stronger turbulence gives stronger deposition as especially interception strengthens.

The simulated wind velocity is only $1-2 \mathrm{~m} \mathrm{~s}^{-1}$ within the vegetative canopy and therefore Brownian diffusion is emphasised. The low wind velocity leads predominantly to removal of freshly nucleated and Aitken mode particles. 

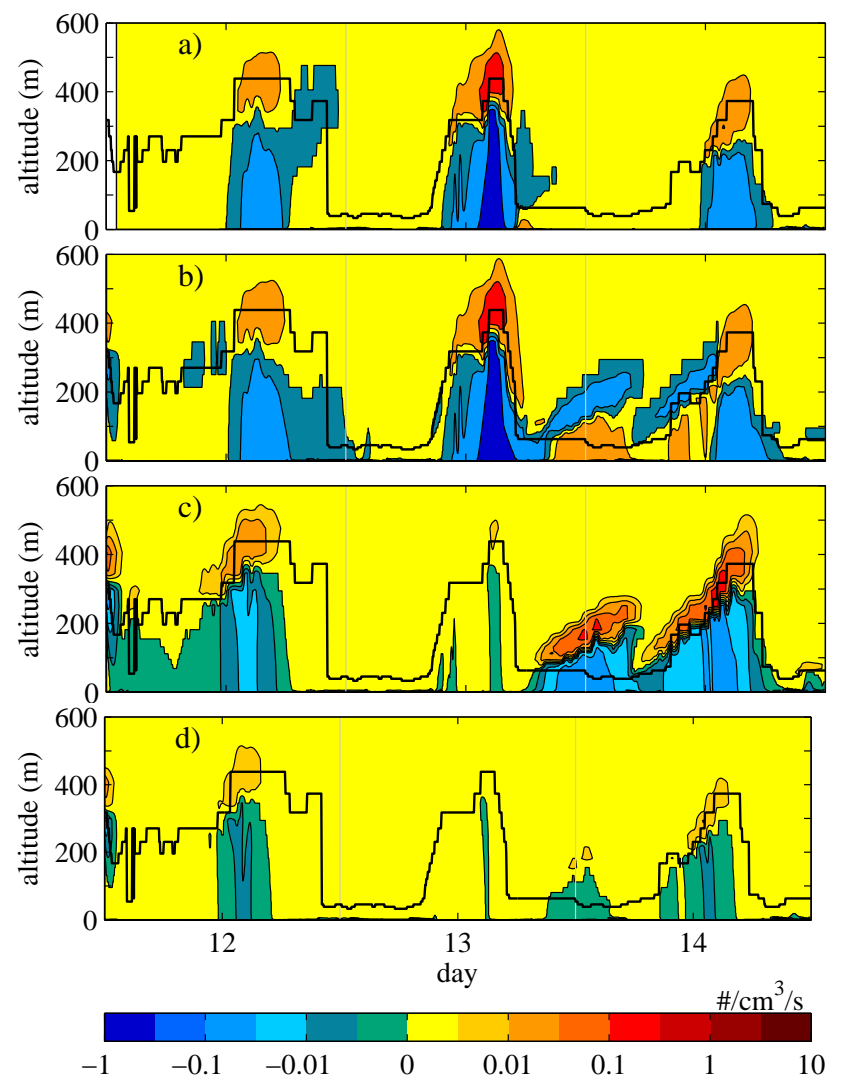

Fig. 6. Effect of turbulent flux on (a) 3-6 nm (b) 3-25 nm, (c) 25$100 \mathrm{~nm}$ and (d) $100-1000 \mathrm{~nm}$ particle concentration calculated as $-d F_{t} / d z$. Black solid curve represents simulated mixing height.

Petroff et al. (2008) already showed that deposition of Aitken mode particles is mainly controlled by Brownian diffusion while Brownian diffusion does not affect similarly concentration of larger particles (Fig. 7). If wind velocity was significantly higher and interception stronger the removal rate of the largest particles could exceed removal rate of Aitken mode particles. However, Brownian diffusion of the smallest particles is so effective that these are removed fastest due to deposition regardless of wind velocity. Therefore deposition as particle sink within forest affected mainly nucleation mode particles. Within the canopy deposition removes the smallest $3-6 \mathrm{~nm}$ particles up to $10 \mathrm{~cm}^{-3} \mathrm{~s}^{-1}$ while the removal rate for $100-1000 \mathrm{~nm}$ particles is only up to $0.1 \mathrm{~cm}^{-3} \mathrm{~s}^{-1}$ (Fig. 8). The removal rates correspond to deposition velocities of the order of $1 \mathrm{~cm} \mathrm{~s}^{-1}$ and $0.01 \mathrm{~cm} \mathrm{~s}^{-1}$, respectively. The diurnal variation in removal rate results from variation in particle concentration. We calculated the total removal flux of particles due to deposition in the vegetational column. Dividing the total flux by the particle concentration above the canopy we can compare the results with observed deposition velocities. In the simulations the median normalised deposition velocity $v_{d} / u_{*}$ is $8 \times 10^{-3}$ for $10 \mathrm{~nm}$ particles and the minimum $6 \times 10^{-4}$ is achieved
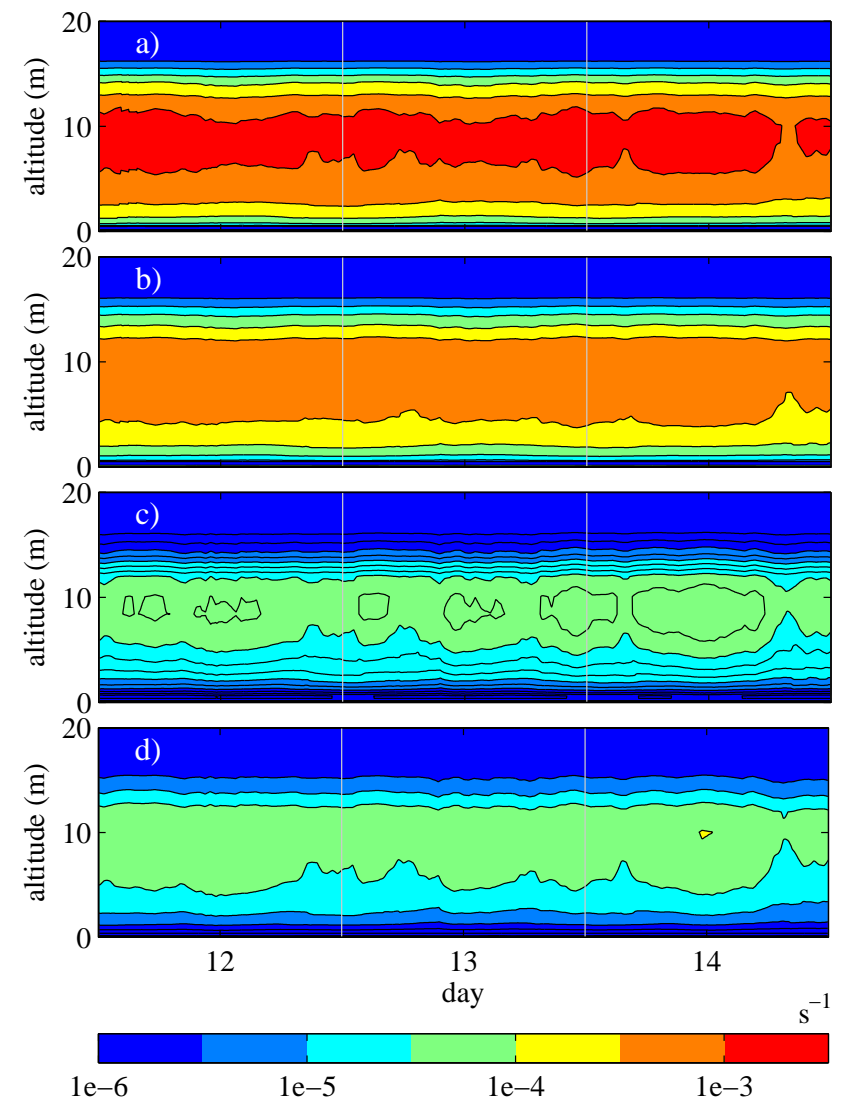

Fig. 7. Median collection rate of (a) 3-6 nm (b) 3-25 nm, (c) 25$100 \mathrm{~nm}$ and (d) $100-1000 \mathrm{~nm}$ particles. Collection rate is calculated as given by Eq. (3). The height of canopy is $15 \mathrm{~m}$.

around $140 \mathrm{~nm}$. The results are consistent with observations even if the values are slightly smaller than the observed median values (Grönholm et al., 2007; Pryor et al., 2008).

\section{Conclusions}

Our results point out the importance of mixing and a reliable mixing scheme in new particle formation studies. We succeeded to reproduce observed new particle formation events at the surface by applying kinetic and organic-sulphuric acid nucleation theory. The vertical profiles however showed that kinetic nucleation did not correspond to the observed particle formation as the particle concentration became too high above the ABL. Instead organic-induced particle formation resulted in similar surface events and structure of vertical particle profile as the observations. This result indicates that the organic-induced formation mechanism can be responsible for particle formation at a Boreal forest site. Similar vertical profiles of particles during observed nucleation events have been observed at SMEAR II (Laakso et al., 2007; O'Dowd et al., 2009) and at other locations (e.g. Stratmann et al., 2003). Thus this mechanism could be an important path to atmospheric nucleation over forested areas and potentially 


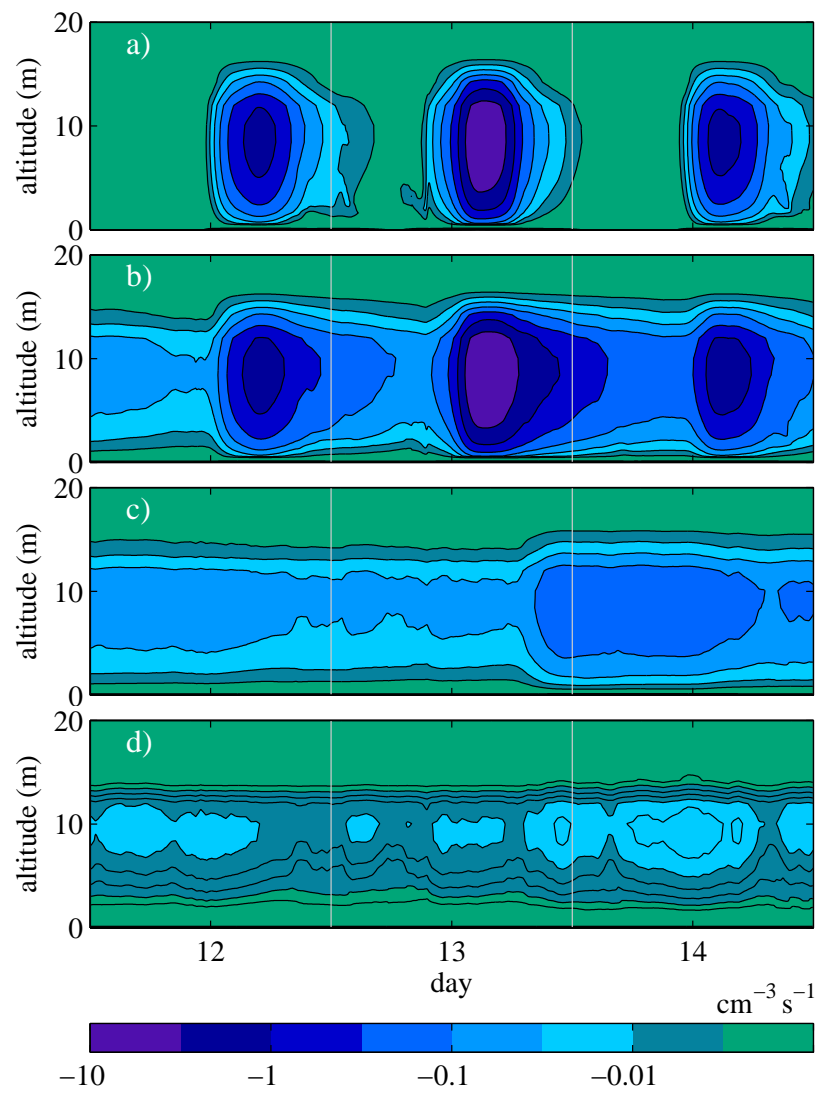

Fig. 8. Removal rate $\left(\mathrm{cm}^{-3} \mathrm{~s}^{-1}\right)$ due to deposition for (a) 3-6 nm (b) $3-25 \mathrm{~nm}$, (c) $25-100 \mathrm{~nm}$ and (d) $100-1000 \mathrm{~nm}$ particles. Removal rate is calculated as given by Eq. (4).

also at other areas where emission of organic compounds occurs.

The underestimation of mixing led to overestimated gradient in vapour concentration at the top of the mixed layer. As the nucleation and condensing vapour concentration were probably underestimated, we were not able to reproduce particle formation processes above the ABL convincingly. The importance of reliable mixing scheme for top of the ABL and layers above the $\mathrm{ABL}$ is emphasised when particle formation is considered.

The particle concentration and flux dynamics within the ABL was mainly driven by particle formation, aerosol dynamical processes (growth to next size class) and atmospheric mixing. Deposition affected mostly particle concentration near the surface, and especially concentration of the smallest particles, but ignoring the deposition process did not change particle fluxes substantially. Therefore deposition had minor effect in comparison to particle dynamical processes and atmospheric mixing in our study. The conclusion applies to highly dynamical conditions of particle concentration and fluxes within the ABL without implication to long-term significance of deposition mechanisms for particle removal from the atmosphere.
Acknowledgements. This work was supported by the Helsinki University Centre for Environment (HENVI), the Academy of Finland (project number: 1126009), the European Integrated Project on Aerosol Cloud Climate and Air Quality Interactions (EUCAARI) and the Maj and Tor Nessling foundation (project number: 2009253). The financial support by the Academy of Finland Centre of Excellence program (project number: 1118615) is gratefully acknowledged.

Edited by: E. Swietlicki

\section{References}

Birmili, W., Berresheim, H., Plass-Dülmer, C., Elste, T., Gilge, S., Wiedensohler, A., and Uhrner, U.: The Hohenpeissenberg aerosol formation experiment (HAFEX): a longterm study including size-resolved aerosol, $\mathrm{H}_{2} \mathrm{SO}_{4}, \mathrm{OH}$, and monoterpenes measurements, Atmos. Chem. Phys., 3, 361-376, doi:10.5194/acp-3-361-2003, 2003.

Bonn, B., Boy, M., Kulmala, M., Groth, A., Trawny, K., Borchert, S., and Jacobi, S.: A new parametrization for ambient particle formation over coniferous forests and its potential implications for the future, Atmos. Chem. Phys., 9, 8079-8090, doi:10.5194/acp-9-8079-2009, 2009.

Boy, M., Petäjä, T., Dal Maso, M., Rannik, Ü., Rinne, J., Aalto, P., Laaksonen, A., Vaattovaara, P., Joutsensaari, J., Hoffmann, T., Warnke, J., Apostolaki, M., Stephanou, E. G., Tsapakis, M., Kouvarakis, A., Pio, C., Carvalho, A., Römpp, A., Moortgat, G., Spirig, C., Guenther, A., Greenberg, J., Ciccioli, P., and Kulmala, M.: Overview of the field measurement campaign in Hyytiälä, August 2001 in the framework of the EU project OSOA, Atmos. Chem. Phys., 4, 657-678, doi:10.5194/acp-4-657-2004, 2004.

Boy, M., Kulmala, M., Ruuskanen, T. M., Pihlatie, M., Reissell, A., Aalto, P. P., Keronen, P., Dal Maso, M., Hellen, H., Hakola, H., Jansson, R., Hanke, M., and Arnold, F.: Sulphuric acid closure and contribution to nucleation mode particle growth, Atmos. Chem. Phys., 5, 863-878, doi:10.5194/acp-5-863-2005, 2005.

Boy, M., Hellmuth, O., Korhonen, H., Nilsson, E. D., ReVelle, D., Turnipseed, A., Arnold, F., and Kulmala, M.: MALTE - model to predict new aerosol formation in the lower troposphere, Atmos. Chem. Phys., 6, 4499-4517, doi:10.5194/acp-6-4499-2006, 2006.

Boy, M., Kazil, J., Lovejoy, E., Guenther, A., and Kulmala, M.: Relevance of ion-induced nucleation of sulfuric acid and water in the lower troposphere over the boreal forest at northern latitudes, Atmos. Res., 90, 151-158, doi:10.1016/j.atmosres.2008.01.002, 2008.

Boy, M., Sogachev, A., Lauros, J., Zhou, L., Guenther, A., and Smolander, S.: SOSA - a new model to simulate the concentrations of organic vapours and sulphuric acid inside the ABL Part 1: Model description and initial evaluation, Atmos. Chem. Phys., 11, 43-51, doi:10.5194/acp-11-43-2011, 2011.

Damian, V.: The kinetic preprocessor KPP-a software environment for solving chemical kinetics, Computers \& Chemical Engineering, 26, 1567-1579, doi:10.1016/S0098-1354(02)00128$\mathrm{X}, 2002$.

Gagné, S., Laakso, L., Petäjä, T., Kerminen, V.-M., and Kulmala, M.: Analysis of one year of Ion-DMPS data from the SMEAR 
II station, Finland, Tellus, 60B, 318-329, doi:10.1111/j.16000889.2008.00347.x, 2008.

Guenther, A., Karl, T., Harley, P., Wiedinmyer, C., Palmer, P. I., and Geron, C.: Estimates of global terrestrial isoprene emissions using MEGAN (Model of Emissions of Gases and Aerosols from Nature), Atmos. Chem. Phys., 6, 3181-3210, doi:10.5194/acp-63181-2006, 2006.

Grönholm, T., Aalto, P. P., Hiltunen, V., Rannik, Ü., Rinne, J., Laakso, L., Hyvönen, S., Vesala, T., and Kulmala, M.: Measurements of aerosol particle dry deposition velocity using the relaxed eddy accumulation technique, Tellus, 59B, 381-386, doi:10.1111/j.1600-0889.2007.00268.x, 2007.

Hao, L. Q., Yli-Pirilä, P., Tiitta, P., Romakkaniemi, S., Vaattovaara, P., Kajos, M. K., Rinne, J., Heijari, J., Kortelainen, A., Miettinen, P., Kroll, J. H., Holopainen, J. K., Smith, J. N., Joutsensaari, J., Kulmala, M., Worsnop, D. R., and Laaksonen, A.: New particle formation from the oxidation of direct emissions of pine seedlings, Atmos. Chem. Phys., 9, 8121-8137, doi:10.5194/acp9-8121-2009, 2009.

Hellmuth, O.: Columnar modelling of nucleation burst evolution in the convective boundary layer - first results from a feasibility study Part I: Modelling approach, Atmos. Chem. Phys., 6, 41754214, doi:10.5194/acp-6-4175-2006, 2006a.

Hellmuth, O.: Columnar modelling of nucleation burst evolution in the convective boundary layer - first results from a feasibility study Part II: Meteorological characterisation, Atmos. Chem. Phys., 6, 4215-4230, doi:10.5194/acp-6-4215-2006, 2006b.

Hellmuth, O.: Columnar modelling of nucleation burst evolution in the convective boundary layer - first results from a feasibility study Part III: Preliminary results on physicochemical model performance using two "clean air mass" reference scenarios, Atmos. Chem. Phys., 6, 4231-4251, doi:10.5194/acp-6-4231-2006, 2006c.

Hellmuth, O.: Columnar modelling of nucleation burst evolution in the convective boundary layer - first results from a feasibility study Part IV: A compilation of previous observations for valuation of simulation results from a columnar modelling study, Atmos. Chem. Phys., 6, 4253-4274, doi:10.5194/acp-6-4253-2006, 2006d.

Hoppel, W., Frick, G., Fitzgerald, J., and Larsson, R.: Marine boundary layer measurements of new particle formation and the effects nonprecipitating clouds have on aerosol size distributions, J. Geophys. Res., 99, 14443-14459, 1994.

Korhonen, H., Lehtinen, K. E. J., and Kulmala, M.: Multicomponent aerosol dynamics model UHMA: model development and validation, Atmos. Chem. Phys., 4, 757-771, doi:10.5194/acp-4757-2004, 2004.

Kuang, C., McMurry, P., McCormick, A., and Eisele, F.: Dependence of nucleation rates on sulfuric acid vapor concentration in diverse atmospheric locations, J. Geophys. Res., 113, D10209, doi:10.1029/2007JD009253, 2008.

Kulmala, M., Hämeri, K. K., Aalto, P., Mäkelä, J., Pirjola, L., Nilsson, E. D., Buzorius, G., Rannik, Ü., Dal Maso, M., Seidl, W., Hoffmann, T., Jansson, R., Hansson, H.-C., O'Dowd, C., and Viisanen, Y.: Overview of the international project on biogenic aerosol formation in the boreal forest (BIOFOR), Tellus B, 53, 324-343, 2001.

Kulmala, M., Kerminen, V.-M., Anttila, T., Laaksonen, A., and O'Dowd, C. D.: Organic aerosol formation via sul- phate cluster activation, J. Geophys. Res., 109, D04205, doi:10.1029/2003JD003961, 2004.

Kulmala, M., Lehtinen, K. E. J., and Laaksonen, A.: Cluster activation theory as an explanation of the linear dependence between formation rate of $3 \mathrm{~nm}$ particles and sulphuric acid concentration, Atmos. Chem. Phys., 6, 787-793, doi:10.5194/acp-6-787-2006, 2006.

Laakso, L., Anttila, T., Lehtinen, K. E. J., Aalto, P. P., Kulmala, M., Hõrrak, U., Paatero, J., Hanke, M., and Arnold, F.: Kinetic nucleation and ions in boreal forest particle formation events, Atmos. Chem. Phys., 4, 2353-2366, doi:10.5194/acp-4-2353-2004, 2004.

Laakso, L., Grönholm, T., Kulmala, L., Haapanala, S., Hirsikko, A., Lovejoy, E. R., Kazil, J., Kurtén, T., Boy, M., Nilsson, E. D., Sogachev, A., Riipinen, I., Stratmann, F., and Kulmala, M.: Hotair balloon as a platform for boundary layer profile measurements during particle formation, Boreal Environ. Res., 12, 279-294, 2007.

Lauros, J., Nilsson, E. D., Dal Maso, M., and Kulmala, M.: Contribution of mixing in the ABL to new particle formation based on observations, Atmos. Chem. Phys., 7, 4781-4792, doi:10.5194/acp-7-4781-2007, 2007.

Makkonen, R., Asmi, A., Korhonen, H., Kokkola, H., Järvenoja, S., Räisänen, P., Lehtinen, K. E. J., Laaksonen, A., Kerminen, V.M., Järvinen, H., Lohmann, U., Bennartz, R., Feichter, J., and Kulmala, M.: Sensitivity of aerosol concentrations and cloud properties to nucleation and secondary organic distribution in ECHAM5-HAM global circulation model, Atmos. Chem. Phys., 9, 1747-1766, doi:10.5194/acp-9-1747-2009, 2009.

Manninen, H. E., Nieminen, T., Riipinen, I., Yli-Juuti, T., Gagné, S., Asmi, E., Aalto, P. P., Petäjä, T., Kerminen, V.-M., and Kulmala, M.: Charged and total particle formation and growth rates during EUCAARI 2007 campaign in Hyytiälä, Atmos. Chem. Phys., 9, 4077-4089, doi:10.5194/acp-9-4077-2009, 2009.

McMurry, P. and Friedlander, S.: New particle formation in the presence of an aerosol, Atmos. Environ., 13, 1635-1651, doi:10.1016/0004-6981(79)90322-6, 1979.

Napari, I., Noppel, M., Vehkamäki, H., and Kulmala, M.: An improved model for ternary nucleation of sulfuric acid-ammoniawater, J. Chem. Phys., 116, 4221-4227, 2002.

Noh, Y., Cheon, W. G., Hong, S.-Y., and Raasch, S.: Improvement of the K-profile model for the planetary boundary layer based on large eddy simulation data, Bound. Lay. Meteor., 107, 401-427, 2003.

O’Dowd, C. D., Yoon, Y. J., Junkermann, W., Aalto, P., Kulmala, M., Lihavainen, H., and Viisanen, Y.: Airborne measurements of nucleation mode particles II: boreal forest nucleation events, Atmos. Chem. Phys., 9, 937-944, doi:10.5194/acp-9-937-2009, 2009.

Paasonen, P., Nieminen, T., Asmi, E., Manninen, H. E., Petäjä, T., Plass-Dülmer, C., Flentje, H., Birmili, W., Wiedensohler, A., Hõrrak, U., Metzger, A., Hamed, A., Laaksonen, A., Facchini, M. C., Kerminen, V.-M., and Kulmala, M.: On the roles of sulphuric acid and low-volatility organic vapours in the initial steps of atmospheric new particle formation, Atmos. Chem. Phys., 10, 11223-11242, doi:10.5194/acp-10-11223-2010, 2010.

Petroff, A., Mailliat, A., Amielh, M., and Anselmet, F.: Aerosol dry deposition on vegetative canopies. Part II: A new modelling approach and applications, Atmos. Environ., 42, 3654-3683, 
doi:10.1016/j.atmosenv.2007.12.060, 2008.

Petäjä, T., Mauldin, III, R. L., Kosciuch, E., McGrath, J., Nieminen, T., Paasonen, P., Boy, M., Adamov, A., Kotiaho, T., and Kulmala, M.: Sulfuric acid and $\mathrm{OH}$ concentrations in a boreal forest site, Atmos. Chem. Phys., 9, 7435-7448, doi:10.5194/acp9-7435-2009, 2009.

Pryor, S., Gallagher, M., Sievering, H., Larsen, S., Barthelmie, R., Birsan, F., Nemitz, E., Rinne, J., Kulmala, M., Grönholm, T., Taipale, R., and Vesala, T.: A review of measurement and modelling results of particle atmosphere-surface exchange, Tellus B, 60, 42-75, doi:10.1111/j.1600-0889.2007.00298.x, 2008.

Radhakrishnan, K. and Hindmarsh, A. C.: Description and Use of LSODE, the Livermore Solver for Ordinary Differential Equations, Tech. Rep. report UCRL-ID-113855, Lawrence Livermore National Laboratory, 1993.

Rannik, Ü., Aalto, P., Keronen, P., Vesala, T., and Kulmala, M.: Interpretation of aerosol particle fluxes over a pine forest: Dry deposition and random errors, J. Geophys. Res., 108, 4544, doi:10.1029/2003JD003542, 2003.

Riipinen, I., Sihto, S.-L., Kulmala, M., Arnold, F., Dal Maso, M., Birmili, W., Saarnio, K., Teinilä, K., Kerminen, V.-M., Laaksonen, A., and Lehtinen, K. E. J.: Connections between atmospheric sulphuric acid and new particle formation during QUEST III-IV campaigns in Heidelberg and Hyytiälä, Atmos. Chem. Phys., 7, 1899-1914, doi:10.5194/acp-7-1899-2007, 2007.

Sandu, A. and Sander, R.: Technical note: Simulating chemical systems in Fortran90 and Matlab with the Kinetic PreProcessor KPP-2.1, Atmos. Chem. Phys., 6, 187-195, doi:10.5194/acp-6187-2006, 2006.

Sandu, A., Verwer, J. G., Loon, M. V., Carmichael, G. R., Potra, F. A., Dabdub, D., and Seinfeld, J. H.: Benchmarking stiff ode solvers for atmospheric chemistry problems-I. implicit vs explicit, Atmos. Environ., 31, 3151-3166, doi:10.1016/S13522310(97)00059-9, 1997.

Sihto, S.-L., Kulmala, M., Kerminen, V.-M., Dal Maso, M., Petäjä, T., Riipinen, I., Korhonen, H., Arnold, F., Janson, R., Boy, M., Laaksonen, A., and Lehtinen, K. E. J.: Atmospheric sulphuric acid and aerosol formation: implications from atmospheric measurements for nucleation and early growth mechanisms, Atmos. Chem. Phys., 6, 4079-4091, doi:10.5194/acp-6-4079-2006, 2006.
Sihto, S.-L., Vuollekoski, H., Leppä, J., Riipinen, I., Kerminen, V.M., Korhonen, H., Lehtinen, K. E. J., Boy, M., and Kulmala, M.: Aerosol dynamics simulations on the connection of sulphuric acid and new particle formation, Atmos. Chem. Phys., 9, 2933 2947, doi:10.5194/acp-9-2933-2009, 2009.

Sogachev, A.: A note on two-equation closure modelling of canopy flow, Bound. Lay. Meteorol., 130, 423-435, 2009.

Sogachev, A. and Panferov, O.: Modification of two-equation models to account for plant drag, Bound. Lay. Meteorol., 121, 229266, doi:10.1007/s10546-006-9073-5, 2006.

Sogachev, A., Menzhulin, G. V., Heimann, M., and Lloyd, J.: A simple three-dimensional canopy - planetary boundary layer simulation model for scalar concentrations and fluxes, Tellus, 54B, 784-819, 2002.

Stratmann, F., Siebert, H., Spindler, G., Wehner, B., Althausen, D., Heintzenberg, J., Hellmuth, O., Rinke, R., Schmieder, U., Seidel, C., Tuch, T., Uhrner, U., Wiedensohler, A., Wandinger, U., Wendisch, M., Schell, D., and Stohl, A.: New-particle formation events in a continental boundary layer: first results from the SATURN experiment, Atmos. Chem. Phys., 3, 1445-1459, doi:10.5194/acp-3-1445-2003, 2003.

Stull, R. B.: An Introduction to Boundary Layer Meteorology, Kluwer Academic Publishers, Dordrecht, The Netherlands, 670 p., ISBN: 90-227-2969-4, 1989.

Vehkamäki, H., Kulmala, M., Lehtinen, K., Timmreck, C., Noppel, M., and Laaksonen, A.: An Improved Parameterization for Sulfuric Acid-water Nucleation Rates for Tropospheric and Stratospheric Conditions, J. Geophys. Res., 107, 4622, doi:10.1029/2002JD002184, 2002.

Vuollekoski, H., Nieminen, T., Paasonen, P., Sihto, S.-L., Boy, M., Manninen, H., Lehtinen, K. E. J., Kerminen, V.-M., and Kulmala, M.: Atmospheric nucleation and initial steps of particle growth: numerical comparison of different theories and hypotheses, Atmos. Res., 98, 229-236, doi:10.1016/j.atmosres.2010.04.007, 2010.

Weber, R., Marti, J., McMurry, P., Eisele, F., Tanner, D., and Jefferson, A.: Measured atmospheric new particle formation rates: Implications for nucleation mechanisms, Chem. Eng. Commun., 151, 53-64, 1996.

Weber, R., Marti, J., McMurry, P., Eisele, F., Tanner, D., and Jefferson, A.: Measurements of new particle formation and ultrafine particle growth rates at a clean continental site, J. Geophys. Res., 102, 4375-4385, 1997. 